\title{
(Co)memorar maio de 1968: o imaginário anarquista e a liderança negativa
}

\author{
Patrícia do Prado Ferreira* (1) \\ Universidade de São Paulo, Psicologia Clínica. São Paulo, SP, Brasil
}

Resumo: Em 2018, os "acontecimentos de Maio de 1968" co-memoraram cinquenta anos. No Brasil, comemorávamos os cinco anos de junho de 2013, uma parte do composto do "ciclo de lutas". Esses dois momentos têm em comum, entre outras coisas, o fato de nos fazer pensá-los ainda hoje, pois, apesar de terem findado enquanto ato, eles continuam a existir em termos de afeto e efeito. Eles fazem parte de uma memória coletiva, de uma comemória, que permite que se participe junto em razão daquilo que deixaram no tempo depois. São significados, sentidos e restos que se manifestam no campo sócio-político e no campo de uma subjetividade coletiva. Neste trabalho, destaco dois elementos similares de tais eventos: o imaginário anarquista que os caracterizou e também a consolidação do que denomino de "liderança negativada". A psicanálise serve como suporte teórico para as considerações, especialmente no que tange à questão do que se repete.

Palavras-chave: liderança, coletividade, Maio de 1968, ciclo de lutas, psicanálise.

\section{Maio de 1968 ou sobre frestas do campo político}

Em 9 de maio de 2018, organizei, junto a outros colegas, o evento sobre as Repercussões de maio de 1968 e/na Psicanálise no Laboratório de Psicanálise, Sociedade e Política do Instituto de Psicologia da Universidade de São Paulo, supervisionado pela professora dra. Miriam Debieux. Ficamos uma tarde toda praticando o exercício de pensar a psicanálise no contexto de 1968; as interlocuções de Jacques Lacan neste tempo; o que é possível pensar a partir das contribuições de Sigmund Freud; o que é razoável trazer para o nosso agora; os testemunhos daqueles que estiveram em 1968 e os desdobramentos nos netos dos "revolucionários". Diante de todas essas frentes que discutimos, tornou-se manifesto que Maio de 1968 ainda não se esgotou e fez visível sua impossibilidade intrínseca de um único caminho de leitura, de uma "totalidade" que situe aquele evento em uma composição única - o que indica sua heterogeneidade e complexidade.

Narro isso para dizer de onde parte a contribuição que faço, pois talvez se permita evidenciar uma vez mais esse caráter de que Maio de 1968 foi/é uma atualização e se atualiza toda vez em que disputas, ideias ou estruturas "descem às ruas". Ou, como escreveram Deleuze \& Guattari (1984/2015): "Mas o próprio acontecimento, por mais antigo que seja, não se deixa ultrapassar: ele é abertura de possível. Ele passa para dentro dos indivíduos, tanto quanto para dentro da espessura de uma sociedade" (p. 119).

* Endereço para correspondência: ppferreira01@gmail.com
O recorte deste trabalho é atravessado pela pesquisa que realizo no pós-doutorado ${ }^{1}$, que tem como objeto os desdobramentos do mais recente "ciclo de lutas nacional" - junho de 2013 - que compõe a onda de protestos dos eventos de ocupação das praças e ruas iniciada em 2011 no Egito e que se desenvolveu até a Place de la Republique, com o Nuit Debout, na França, de 2016. Apesar de inúmeras distinções entre este ciclo e Maio de 1968, compreendo que ambos se situam em um momento de lutas generalizado e atuaram enquanto marcas temporais nos locais onde aconteceram. Ressalto que, embora 1968 seja comumente associado à França, ele não estava localizado somente lá, era uma força enérgica que se espalhou por diversos países, até mesmo no Brasil.

Quando fui convocada a falar com o tema específico de Maio de 1968, compreendi que caberia trazer como provocação de exercício de pensamento dois pontos atuais que trabalho em minha pesquisa e que, em meu entendimento, poderiam servir para pensarmos o cenário de Maio de 1968: a ideia de um imaginário anarquista e uma crise de liderança generalizada, que se desdobra em dois polos, destacando o que nomeio liderança negativa ou negativada em contraponto à liderança tradicional ou positivada.

No entanto é necessário marcar que não estou equivalendo ou sobrepondo um momento a outro. São momentos distintos de luta e de contexto sociopolítico, assim como dos seus atores e questões principais. Daniel Cohn-Bendit (2008), considerado um dos "líderes" do Maio de 1968 francês, aconselhou, na ocasião da (co) memoração dos quarenta anos, que Maio de 1968 fosse esquecido, pois ele havia acabado e a sociedade de hoje

\footnotetext{
1 Pesquisa realizada entre 2015-2020 com bolsa pela Fundação de Amparo à Pesquisa do Estado de São Paulo (Fapesp), no Departamento de Psicologia Clínica do Instituto de Psicologia da Universidade de São Paulo.
} 
não teria relação com a sociedade daquele tempo, pois, ao se nomearem antiautoriários, em suas palavras, eles lutavam contra uma sociedade muito diferente. Obviamente, seria da ordem do impossível dar conta de toda a diferença que compõe a sociedade de Maio de 1968 e a sociedade em que nos encontramos cinquenta anos depois. Por isso, dentre inúmeras disparidades, destaco a existência (ou a ausência) de diferenças na participação dos trabalhadores e a crítica (ou sua ausência) ao capitalismo. Elejo estes pontos uma vez que eles permitem uma visão mais estrutural do momento presente, marcado pela racionalidade neoliberal. Ao contrário do que ocorreu em junho de 2013 no Brasil, no qual não houve qualquer destaque relacionado à participação dos trabalhadores ou uma crítica centrada nos efeitos nefastos do capitalismo, Maio de 1968 foi um momento em que existiu um forte protagonismo dos trabalhadores ao lado dos estudantes e no qual a criticidade ao sistema permeou os dias de luta.

Bernardo (2008) encontrou, em sua pesquisa em de jornais e panfletos franceses publicados em época, três temas principais: "a recusa de uma universidade ao serviço do capital, a defesa dos interesses dos trabalhadores no interior da universidade e a aliança entre intelectuais e trabalhadores" (p. 23), ficando evidente ao longo de seu relato investigativo que a luta dos estudantes estava diretamente associada à luta dos trabalhadores: "estudantes com os trabalhadores" era o que estava escrito na faixa que abria a manifestação em 7 de maio. A forma dessa união era compreendida diferentemente por cada bloco que compunha o Maio de 1968 francês, e é também dessa união que se realiza a greve geral. Não entrarei nos pormenores, pois meu objetivo não é esmiuçar tal aliança e seus desfechos, mas gostaria de assinalar que os atores de 1968 trabalharam juntos, uniram-se em um esforço organizado para que uma causa pudesse fortalecer a outra.

Essa conjunção esbarra diretamente no segundo ponto que gostaria de destacar do maio francês, pois o enredo ou o fio condutor entre estudantes e trabalhadores se encontrava na crítica que realizavam ao capitalismo e suas formas de expressão. A crítica se concentrava sumariamente na exploração capitalista que afetava os trabalhadores e na recusa dos estudantes em ocuparem o lugar de futuros agentes da burguesia. Esse também não era um mote sem conflitos e, como retratado por Bernardo (2008), ocupava a pauta dos panfletos, como em um que data de 8 de maio, no qual o Movimento do 22 de Março, junto ao Comitê de Ação dos Liceus, escreve: "estudantes recusam tornar-se quadros cúmplices e beneficiários da exploração dos trabalhadores. . . . Nós não queremos ser os cães de guarda do Capital", assim por diante. Além disso, havia uma série de vicissitudes compondo o cenário e o imaginário de 1968. Ferreira (2018) elenca elementos que vão desde a Segunda Guerra (1939-1945), passando pela literatura, com obras de Jack Kerouac e Allen Ginsberg; as lutas pela independência nacional de países colonizados, como a Guerra da Argélia (1954-1962) e a Guerra do Vietnã (1959-1975); e os movimentos cívicos afro-americanos nos Estados Unidos. Ainda de acordo com Ferreira (2018), os modelos ideológicos, que eram defendidos sobretudo pelos estudantes de 1968, estavam alinhados primeiramente aos maoístas - como efeito da revolução cultural chinesa em 1966 e da liderança de Mao Tsé-Tung -, depois aos trotskistas e, ainda, aos castristas e aos guevaristas, apontando para o horizonte comunista. Entretanto Ferreira (2018) afirma que, a partir da Assembleia Geral de 22 de março de 1968, na qual os estudantes da Universidade de Paris Nanterre X se reuniram em defesa da libertação de um estudante preso ao se manifestar contra a Guerra do Vietnã, algo em forma de espontaneidade e informalidade emerge, "assim como a auto-organização e a democracia direta. . . . A luta contra o Estado e o capitalismo, por outro lado, passou a estar na ordem do dia, sem que para o efeito fossem necessários chefes, partidos, sindicatos ou burocratas de qualquer espécie" (p. 26). Em seu entendimento, é possível afirmar que a grande maioria eram libertários, na medida em que não tinham partido ou ideologias. Voltarei a esse ponto mais adiante, quando considerar mais precisamente o "imaginário anarquista". Por ora, volto à rememoração.

$\mathrm{Na}$ ocasião dos quarenta anos de Maio, Alain Badiou (2009/2012) indagou se o rebuliço da comemoração seria uma tendência a ilustrar o apagamento da memória revolucionária, como uma intenção de mostrar que ela "não deu certo" ou que o que ficou foi o modo como maio foi apropriado pelo capitalismo; apontando, como contraponto, para a comemoração de Maio como uma fonte de inspiração, como um "poema histórico, para recobrar a coragem, para realmente reagir, quando se chega ao fundo do buraco" (p. 30). Agora acho que vale a pena revisitar com a mesma desconfiança neste momento de rememoração, sem deixar de nos atermos ao fato de que recordar ou repetir podem fazer parte de um processo de elaboração. Revisitamos os cinquenta anos de Maio de 1968; sete anos depois de 2011; cinco anos depois de 2013; em mais um momento de carência de fontes de inspiração. Esses momentos ou acontecimentos que, em comum, como sugerem Deleuze \& Guattari (1984/2015), teriam a marca de um fenômeno coletivo em busca de um possível, de uma possibilidade para outra coisa e que cria "uma nova existência, produz uma nova subjetividade (novas relações com o corpo, o tempo, a sexualidade, o meio, a cultura, o trabalho. . .)" (p. 119). Isso existiria ao menos enquanto potência, mas não quer dizer que tenha de fato se concretizado - pelo menos não da forma como se imaginou, planejou, sonhou. Aqui é possível que esteja um ponto de Maio que vem sendo afirmado nos seus cinquenta anos, e talvez essa análise seja ainda mais contundente quando se tece comparações com o ciclo de lutas que igualmente é analisado com reticências e desconfianças diante do que poderia ter sido e não foi. Sem esquecer, claro, do caráter de idealização de todos esses processos, da descarga de afetos, como a esperança e o medo que despertou nos apoiadores e nos opositores. 
Então, para que recordar? Quando voltamos a Freud (1914/1996), recordar tem a ver com o trabalho hipnótico que ele realizava, como uma "reprodução" conciliadora, a fim de que se restaurasse ou se recuperasse uma cena traumática. Recordar, no sentido dado pela psicanálise freudiana, é como uma busca do momento em que o sintoma se instaura, tendo como objetivo um efeito terapêutico na descarga das emoções. Mas logo ele descobre que nem sempre é possível recordar o que está recalcado e que, muitas vezes, o paciente atua por meio da repetição, sem saber que assim o faz. Ou seja, a repetição seria como a atualização da cena que colocaria em evidência a atualidade da cena, a atualidade de uma força.

A elaboração entraria como elemento complementar, como modo de lidar com a resistência em recordar, que compõe a repetição. Ela é necessária para o processo de simbolização. Freud estava se referindo à prática clínica com pacientes, mas aqui, como lugar de experimento, arrisco dizer que talvez também seja possível apostar e trazer essa ideia dos três componentes na tentativa de pensar a importância de algo que quiçá esteja nos escapando: (co)memorar, trazer a memória em conjunto, Maio de 1968 ou esse movimento de "volta" possui traços de repetição? Isto é: existe algo que tem escapado aos eventos de Maio de 1968 ou apenas recordamos como uma lembrança que nos remete a um tempo de abertura para outro possível, de esperança ou de fracasso, como desconfiou Badiou há dez anos?

Quando Lacan (1964/1985) se ocupa da repetição, ele a coloca em relação ao objeto $a$, a falta estrutural do sujeito, ao elemento fundamental para as relações objetais, que indica o furo próprio da linguagem. E, para dizer disso, no Seminário 11, Lacan retoma a questão da repetição utilizando as ideias aristotélicas de tiquê e autômaton. De forma concisa e para se ter uma imagem de diferenciação entre uma coisa e outra, pode-se dizer que no autômaton se trata de uma insistência em voltar dos signos, como no princípio do prazer, enquanto a tiquê é constituída por algo para além disso ou para além do princípio do prazer, como sugerem as palavras de Lacan: "encontro do real" (1964/1985, p. 56).

A função da tiquê, do real como encontro - o encontro enquanto que podendo faltar, enquanto que essencialmente é encontro faltoso - se apresenta primeiro, na história da psicanálise, de uma forma que, só por si, já é suficiente para despertar nossa atenção - a do traumatismo. (Lacan, 1964/1985, p. 57)

Repetir implica em uma novidade, "a repetição demanda o novo" (Lacan, 1964/1985, p. 62), isto é: não é possível repetição idêntica, pois existe uma impossibilidade na repetição - isso é que tem relação com o fracasso do encontro; a faceta que tem de real, da marca da falta. É o que permite a Constantin Constantius, da novela Repetição, de Sören Kierkegaard, fazer-se não o esposo, mas poeta.

\section{O imaginário anarquista}

Voltemos a Maio de 1968, recordando a afirmação considerada polêmica de Lacan no Seminário 17 (19691970/1992), quando ele está no embate com a plateia em Vincennes, um ano depois, em 1969, ainda sob efeitos do que "não aconteceu":

Se tivessem um pouco de paciência, e se aceitassem que nossos improvisos continuassem, eu lhes diria que a aspiração revolucionária só tem uma chance, a de culminar, sempre, no discurso do mestre. Isto é o que a experiência provou. É ao que vocês aspiram como revolucionários, a um mestre. Vocês o terão. (Lacan, 1969-1970/1992, p. 196)

Minha crítica $^{2}$ se situa no uso ao qual essa passagem frequentemente tem servido à psicanálise, o que entendo como entrave de compreensão e de investigação de manifestações e movimentos, de forma similar à utilização da teoria freudiana sobre os grupos, que igualmente parece convir como ponto de apoio para deslegitimar as lutas. Muitas vezes, silencia-se a intenção revolucionária ao afirmar que "querem outro mestre", e as associações coletivas se tornam caducas quando o único entendimento possível é o de que as pessoas perdem sua autonomia quando em grupo, "ou seja: o único destino de um grupo seria o de cair da alienação a um significante mestre" (Ferreira, 2018a, p. 76).

Destaco, no entanto, que é possível compreender a afirmação lacaniana como algo que aloca os "revolucionários" como agentes do discurso histérico e, por essa razão, deveria ser compreendido como distinto de um "movimento histérico" ou de uma histeria coletiva, aos moldes das moças do internato de Freud (1921/1996).

Tomemos o Maio de 1968 francês, no qual a luta se estendia para a queda do general Charles De Gaulle, um mestre a cair. Ao mesmo tempo, questionavam-se autoridades de todos os tipos: colonizadores, tiranos, pastores e as mais variadas tradições. Considero que voltar ao contexto é importante, pois Lacan estava sendo provocado por um grupo de estudantes depois de dizer que a União Soviética e, portanto, os comunistas, eram representantes do discurso universitário. Estamos, certamente, diante de uma crítica de Lacan também à forma da constituição partidária, mas, além disso, é impossível não considerar que Lacan estivesse atacando outros experimentos de organização coletiva que o movimento - seja de estudantes ou dos operários - tentou sustentar durante maio de 1968.

2 Uma discussão mais aprofundada sobre este problema pode ser encontrada no artigo de Ferreira (2018a). 
O trecho a seguir, de Olgaria Matos (1981/1989), descreve como foi a "grande recusa" em várias instâncias durante maio de 1968. Isto é, de que modo os protestadores estavam interessados em questionar a ordem do saber vigente em diferentes frentes, balançando a ordem estabelecida, fazendo questão desde a organização política até de contradições e "valores" culturais:

O ano de 1968 foi o marco da Grande Recusa: recusa dos partidos oficiais, do marxismo burocratizado e do mundo venal, recusa e exigência de transformação de valores; quando a revolta acontece em sociedades "prósperas" e "democráticas", ela significa uma recusa moral: a obscenidade não é mais a mulher nua que exibe o púbis, mas o general que exibe a medalha ganha no Vietnã. Não é tampouco, diz Marcuse, o ritual hippie, mas a declaração de um alto dignitário da Igreja que afirma ser a guerra necessária para a paz. (Matos, 1981/1989, p. 36)

Nessa conjuntura, não se pode deixar de considerar que a ocasião de 1968 é um momento que reaviva o imaginário anarquista - levando-se em conta, aqui, a ideia de anarquismo de forma genérica, enquanto oposição a hierarquias de poder, especialmente no que tange a corporações e Estado. Naquele contexto, no entrave composto por estudantes e operários, existiu uma disputa de organização entre os membros da
Juventude Comunista Revolucionária, os sindicatos e as ideias libertárias - no sentido de oposição a um controle de outrem sobre a vida, considerando a autogestão como prática - e anarquistas, que se posicionavam críticas à rigidez e à disciplina comunista. Ainda, as práticas libertárias estavam "ancoradas na ação individual e na ação coletiva revolucionária, nomeadamente na ocupação das fábricas e das universidades, na construção e na luta das barricadas e na sustentabilidade da greve geral" (Ferreira, 2018, p. 26), ao mesmo tempo em que, nas universidades, os estudantes lutavam para que, em sua formação, não houvesse cursos que concordassem com "desígnios superiores da ciência capitalista e tinha, em última análise, como função exclusiva dinamizar a exploração da classe operária e do campesinato" (Ferreira, 2018, p. 29). No entanto, apesar de não serem completamente favoráveis a lideranças, Daniel CohnBendit, ou "Dany Le Rouge", afirmam Besancenot e Löwy, em Afinidades revolucionárias (2016), terminou por assumir essa função na medida em que se colocou como "suficientemente libertário para os anarquistas, suficientemente ponderado para os leninistas" (p. 47). Embora não se possa esquecer outros, entre tantos, que formavam uma espécie de liderança pluralizada, como retrata a foto em que aparecem Alain Geismar (à época, secretário-geral do Sindicato Nacional do Ensino Superior) e Jacques Sauvageot (então vice-presidente da União Nacional dos Estudantes Franceses), além de Cohn-Bendit.

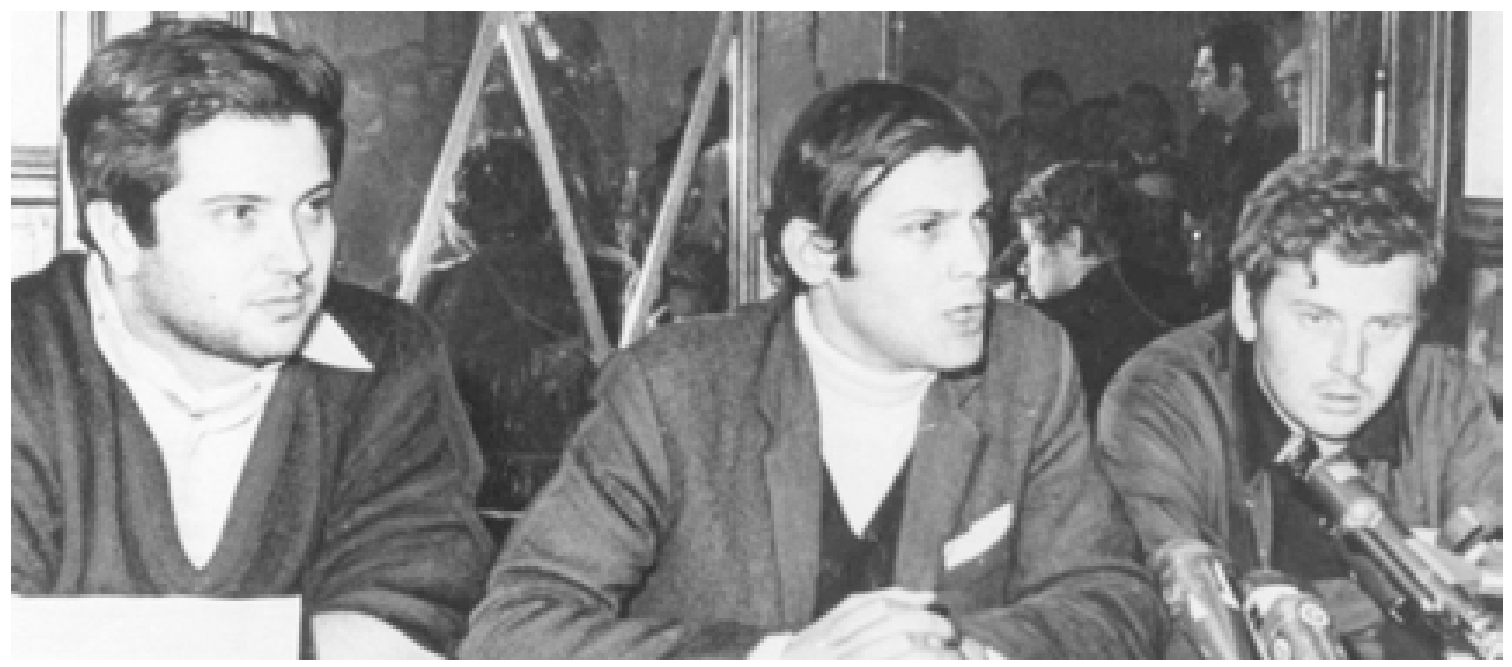

Figura 1.

Alain Geismar, Jacques Sauvageot e Daniel Cohn-Bendit.

Fonte: $\mathrm{O} \mathrm{Globo}^{3}$.

Não se pode referir - e não me refiro - a Maio de 1968 como movimento anarquista stricto sensu, no sentido de seguir ideias e ideais de Proudhon ou de Bakunin, mas

3 Recuperado de https://glo.bo/3h4ANzQ como um momento no qual está presente certo imaginário anarquista, do modo como o pensador espanhol Tomas Ibáñez Gracia (2014) tem considerado, isto é: um "anarquismo extramuros", como uma referência às ideias que se concentram em formas políticas que se pretendem 
anti-hierárquicas, anticentralistas e antirrepresentativas. Ao mesmo tempo, Maio traz à memória algo parecido com o que Badiou nomeou de "Maio libertário", referindo-se à "mudança dos costumes, das novas relações amorosas, da liberdade individual” (Badiou, 2009/2012, p. 32), do surgimento das questões feministas e homoafetivas.

O imaginário anarquista de maio de 1968 se concentrou em uma esfera cultural, mas não só nisso, fazendo a organização não burocrática e horizontalizada se traduzir em uma não organização, evocando um tom de espontaneísmo, de improvisação. É este o ponto que talvez tenha me feito associar o ciclo de lutas de 1968 ao ciclo de lutas de 2011-2016, embora as diferenças sejam muito maiores que suas relações. A questão da organização em 1968 e no começo da segunda década dos anos 2000 tinha esse tom de espontaneísmo, de horizontalidade da negação partidária, embora me pareça que a negação de 1968 à estrutura tradicional de movimentos e manifestações era mais contundente e delineada devido ao cenário histórico-político que destaquei anteriormente. A questão do ciclo mais recente envolve prerrogativas de diferentes ordens e outros "ordenadores", como o uso das tecnologias para organização dos movimentos. Além disso, minha hipótese é de que o rechaço a partidos e lideranças seja original de algo na esfera do ressentimento. Isto é, de um ressentimento que advém como efeito da severa crise representativa que assola a democracia na atualidade, uma espécie de desidentificação aos representantes, ampliando a distância com aqueles que são/deveriam ser representados. Dito isso, é possível afirmar que estes ciclos se arquitetam a partir de narrativas distintas e que estão na forma que encontraram de expressar a existência de descontentamento. Isto é, são manifestações de protesto similares enquanto imagem, pois utilizam da ocupação de espaços públicos, mas que têm causas, efeitos e produção de memória distintos.

Em relação à liderança, podemos considerar que a questão na França ou a referência a "mestres" era tanto no movimento dos operários como também no "Movimento 22 de Março" (considerados pontos de partida do maio francês), um problema que aparecia e era questionado e discutido. Com isso, ganhou maior espaço o imaginário anarquista, sendo possível constatar em livros ou documentários daquela época ${ }^{4}$ a insistência na não personificação de lideranças (embora - e é visível - tenha ocorrido) e na não hierarquização do movimento. As iniciativas tentavam ser decididas em comum acordo em assembleias, e não só executadas a partir de uma ordem dada. Coloco isso para evidenciar ainda mais o tom provocativo da afirmação lacaniana mencionada anteriormente, pois a estruturação coletiva de maio de 1968 partia desde sua origem do questionamento da hierarquização e da

4 No documentário Quartier Latin, realizado em pleno maio de 1968, por exemplo, é possível ver aparecer a questão da liderança e a tentativa de estabelecer outro tipo de organização coletiva. representação coletiva. Estava aqui, assim, marcada a questão da liderança, o dilema político que se mantém em nossos dias, como também esteve presente nos movimentos antiglobalização da década de 1990 e nos movimentos de ocupação das ruas, praças entre 2011 a 2016 - e das escolas pelos secundaristas, em 2015/2016. Agora, retorno à questão da posição histerizada dos revolucionários.

$\mathrm{O}$ sujeito que assume a posição de agente no discurso da histeria é suportado pelo não saber (a); dirigindo-se ao mestre - colocando-o em questão, demandando ou contestando - para provocar o desejo e, com efeito, a produção do saber. Como é sabido, Freud foi provocado pelo não-saber de suas pacientes histéricas, e seu desejo de saber é o pontapé de uma produção notável. Como nos lembra Lacan, a própria ideia de sintoma só pode ser pensada nesses termos, como articulou Marx historicamente: "Que é, a saber, existirem acontecimentos históricos que só podem ser julgados em termos de sintomas" (1969-1970/1992, p. 193) e que é a partir do discurso da histérica que se tem passagem ao discurso no analista. Isso se dá em um movimento dialético entre um e outro, e a "histerização discursiva" é algo que se almeja para uma pessoa enquanto posicionamento em um processo analítico.

No entanto, como adverte Colette Soler (2016), a histeria por si só não é trabalhadora, mas questionadora; histéricos e não histéricos precisam ser histerizados em análise para que se tornem analisantes, isto é, para que o sujeito barrado venha no lugar daquilo que trabalha. O sujeito histerizado é quem dá passagem ao sujeito analisante. Contudo isso só é possível a partir de uma sustentação de direção - que, no caso da análise, cabe ao psicanalista.

\section{Organização coletiva horizontal e liderança negativada}

\author{
Olgaria Matos (1981/1989) afirma:
}

Em 68, o próprio movimento de jovens operários e estudantes praticou a espontaneidade consciente e criadora. Não se considerou o sistema de partidos ou grupos de pressão a qualquer nível; não se participou nem do sistema nem de seus métodos. Desde o início o movimento não tem dirigentes, nem hierarquia, nem disciplina partidária ou outra; ele contesta os profissionais da contestação, viola as regas do jogo que as oposições dominam. . . Com a crítica ao mundo burocratizado e desencantado, colocou como lema a verdade triunfante do desejo. (p. 13)

E, ainda: "O desejo revolucionário será muito mais marcante do que a situação revolucionária. Talvez por isso o movimento foi mais capaz de contestar do que vencer, de imaginar do que transformar, de se exprimir do que se organizar" (Matos, 1981/1989, p. 21). 
Ou seja: o desejo precisa estar implicado para que haja qualquer tipo de movimento. $\mathrm{O}$ que não quer dizer que disso, por si só e magicamente, se obtenha uma transformação, mas que é a partir do desejo que pode haver qualquer tipo de agitação. No entanto, muitas das vezes, não se sabe o que fazer com isso, apesar da potência existente e insistente de fazer algo. Movimentos como Maio de 1968 e o ciclo de lutas de 2011-2016 talvez sirvam como ilustração da distinção entre querer, desejar e realizar. Digo isso pois é possível se apaixonar por um estado desejante, da mesma forma como por uma espécie de estado reivindicante, como no caso do discurso da histeria. Acontece que, para toda essa insatisfação ter efeito em ato, é necessário um direcionamento. Caso contrário, há grandes chances de se cair em um tipo histérico que bradaria somente o descontentamento, o que poderia ser tomado como pura vociferação.

Existe uma considerável distinção nas formas de tentar se organizar desde 1968. Críticos de uma forma tradicional de organização coletiva, os participantes de Maio tentaram colocar em prática outros modos de coletivização. É importante destacar esse caráter, em certo sentido experimental, de transpor algo que talvez não tivesse funcionando tão bem. Rodrigo Nunes (2017) localizou essa distinção organizativa entre dois momentos "revolucionários":

Embora "1917" e "1968" obviamente não passem de abreviaturas para as diversas fidelidades que estes dois eventos inspiraram ao longo dos anos, estas duas datas nos permitem nomear aquilo que permanece, sem sombra de dúvida, o cisma mais importante no interior da esquerda. Para dizê-lo do ponto de vista da organização, embora haja outros tanto ângulos desde onde seria possível fazê-lo: o cisma entre uma esquerda que enfatiza o político em detrimento do social, o que se traduz num apego a formas organizativas tradicionais e, sobretudo, à forma-partido; e uma esquerda que, apesar da variedade de formas organizativas com que experimentou ao longo dos anos, geralmente prefere permanecer próxima aos movimentos sociais, em consonância com sua valorização do social em detrimento do político. (pp. 139-40)

Além disso, destaco a imagem da liderança distribuída, da forma como Nunes (2013) indica, pois tal tipo de liderança não se refere à ausência de líderes, mas a lideranças oportunas ou diretivas, digamos. Nunes destaca que isso não significa que cada indivíduo teria o mesmo peso que qualquer outro em cada momento, até mesmo porque a horizontalidade não tem relação com uma ideia de igualdade absoluta; no entanto todos seriam potencialmente iguais na medida em que são potencialmente líderes. Isto é: novas lideranças, ideias e iniciativas podem emergir a qualquer momento, pois não existem lugares preestabelecidos.

Nestas condições, "direção" não é nem um título vitalício que se adquire por lutas passadas, nem uma propriedade mágica que adere a estruturas formais; é apenas o nome que descreve quem se demonstra, na prática, capaz de direcionar o curso do movimento em um momento dado. "Direção", em resumo, é quem dirige, no momento em que dirige. (Nunes, 2013)

Pensando em grupos e trazendo a discussão (e contribuição) da psicanálise, é importante que possamos discernir como o trabalho teórico e prático também tenta lidar com essa problemática. Um vez mais ${ }^{5}$, volto ao que Lacan havia proposto em 1964 como sugestão que pode ser compreendida com um viés "revolucionário" para grupos, ou seja, a proposta do cartel.

O cartel, órgão de base da Escola de Lacan, propõe uma organização coletiva na escala de $4+1$. Claramente fazendo frente à organização coletiva tradicional, inclusive das escolas de psicanálise, Lacan tentou sustentar outro rearranjo às identificações coletivas. Ele intentou criar um dispositivo que estivesse em contraposição à formações e identificações grupais tais como Freud descreveu. Pode-se também reconhecer a influência dos grupos de trabalhos de Bion, inclusive aludidos por Lacan em seus Outros escritos ${ }^{6}$.

A estruturação do cartel é circular, baseada num princípio de horizontalidade, ou seja, sem que fortaleça ou sustente qualquer tipo de hierarquização. $\mathrm{O}$ trabalho no cartel é o que permite a identificação entre seus membros participantes - aqui, claro, estamos falando de psicanalistas, pois é uma forma organizativa pensada para os trabalhos e estudos psicanalíticos; e é a experiência que sustenta seu funcionamento. Neste formato, é importante que o Outro não sirva como referencial; mas que a referência seja dada a partir do desejo de pesquisa e de saber sobre determinado problema. Além disso, fica incumbido ao mais-um a função de tentar fazer cair tentativas que o coloquem - ou que coloque qualquer outro participante - no lugar de Outro. A tarefa parece simples, mas, em se tratando de sujeitos, ela é bastante complexa, especialmente quando se tenta praticá-la. Poderíamos dizer de forma simples e rápida que a dificuldade no cartel ou em qualquer outro grupo que se pretenda horizontal se dê em três direções: a primeira delas é sustentar seu próprio não-saber sem demandar ao Outro; a segunda é não eleger esse Outro; e a terceira é não se eleger como Outro do saber ou ser fisgado pela sedução de ocupar esse lugar de "poder".

\footnotetext{
5 Outro momento em que me dediquei à questão pode ser verificado em Ferreira (2018b).

6 Para ter acesso a este trabalho, consulte o texto de 1947 de Lacan (1947/2003) intitulado "A psiquiatria inglesa e a Guerra".
} 
Essa dinâmica aponta também para outra problemática: a questão do embate à identificação vertical que sabemos se sustentar quase sempre - o que não é uma regra - pela manutenção de alguma alienação a um Outro. Como sabido, além do dispositivo do cartel, também é possível localizar na prática psicanalítica manifestações de proximidade com certo imaginário anarquista, uma vez que o embate psicanalítico concentra-se, em última instância, na questão do poder. Isso se dá no cartel e também no próprio processo analítico quando se está em questão a sujeição do sujeito ao significante-mestre, quando se questiona o S1, quando a posição do analista é sustentar o lugar do vazio. $\mathrm{Ou}$, ainda, quando a psicanálise coloca em questão as leis - seja do Estado, do exército ou da Igreja, do Outro e qualquer outro processo de alienação.

Assim, voltando à ocasião de Maio de 1968, destaco igualmente este ponto da problemática com a "liderança tradicional" e afirmo que tal crítica, assim como a dos mestres que faz a psicanálise, abre espaço para o que me autorizo a nomear de liderança negativa ou liderança negativada. Ela é um contraponto a ideia do líder tradicional que tem a função de ponto de referência de uma organização coletiva verticalizada, firmada na positividade e na autoridade. A negatividade viria dessa frente que se faz ao Um da fantasia da totalidade, na sua função de fio condutor e de suporte para todos os laços sociais.

A liderança negativada, nesta acepção, é tida como função, não sendo tomada como um negativo puro, uma vez que não se trata do poder como ausência absoluta ou concreta, mas como se, a partir de sua negatividade, as pessoas pudessem detê-lo, dispensando a referência direta, imediata ou dada a priori como materialização identificadora de um coletivo, por exemplo, como ocorre no que entendemos como liderança positiva.

Uma espécie de "unidade coletiva", para trazer uma formulação de Bakunin; algo que implica o sujeito, que diz do dentro e do fora. É assim que vejo a "negatividade" no mais-um do cartel - esse dispositivo que é composto pelo não-saber compartilhado, pelo vazio - quando ele, o mais-um, tem a tarefa de negar as demandas, ao mesmo tempo em que precisa manejar o desejo de saber, assumindo a função de encarregado da seleção, da discussão e do destino a ser reservado ao trabalho de cada um, como sugere Lacan. É também assim que penso que talvez seja possível compreender a função do analista, que ocupa o lugar do vazio em um processo de análise, sabendo do efeito de sua posição, ao mesmo tempo em que precisa estar atento para conduzir a "direção do tratamento". Este vazio não é, portanto, negatividade pura, mas apareceria como um representante da falta. Pois sabemos que na análise o analisante é o principal, mas sem a transferência e a escuta não há meio para a "condução" de um tratamento analítico.

E escutar não é o mesmo que ouvir. Implica apreender aquilo que se vela e desvela dos enunciados, ou seja, é mais do que ouvir a fala a partir de critérios prévios de uma teoria. No campo sociopolítico, as manifestações e os movimentos sociais têm, muitas das vezes, a função de dar voz. Maio de 1968 na França deu voz aos anseios da sociedade francesa; junho de 2013 deu voz às insatisfações com o transporte e, depois, a um descontentamento generalizado; as ocupações nas escolas deram voz aos secundaristas periféricos; as ocupações no Egito deram voz ao sufoco vivido na ditadura; a Puerta del Sol deu voz ao sofrimento sociais dos espanhóis, e assim por diante. A funcionalidade da liderança negativada, no meu entender, deveria implicar em dar lugar privilegiado à escuta do que enunciam as ruas, as manifestações, os movimentos e - por que não? o povo. Uma espécie de mestre ignorante, como aposta Rancière (2002), ou até mesmo em alguns momentos do jovem Daniel Cohn-Bendit que, ao ter sido considerado como "suficientemente libertário para os anarquistas, suficientemente ponderado para os leninistas", parece ter tido algum cuidado em ouvir e dizer.

Para finalizar, busquemos recordar Maio de 68, a Revolução Russa de 1917, a Puerta del Sol em Madri, a Praça Tahir no Egito, a Sintagma em Athenas, o fôlego de junho de 2013, as ocupações nas escolas em 2015, 2016. E, se algo se repetir, sabemos: será uma novidade, haverá produção de saber. Se o que vier for ainda "outro mestre", como insinua a provocação lacaniana, não será idêntico ao anterior, uma vez que existe sempre a possibilidade de produzir outro significante ou de ressignificá-lo. Só assim, nesse processo de recordação e repetição, é possível elaborar e seguir adiante.

\section{Commemorating May 1968: the anarchist imagery and negative leadership}

Abstract: In 2018, 50 years of the 'events of May 1968' were com-memorated. In Brazil, we com-memorated five years of June 2013, part of the compound 'cycle of struggles'. Both moments incite us to think about them even today. Although they ended as an act, their existence nowadays consists of affection and effect. They are part of collective memory, a co-memory that allows experiences based on what they have produced. In terms of meanings, thoughts and remains that are manifested in the sociopolitical and 'collective subjectivity' fields. In this paper, I highlight two related elements of such events: the anarchist imaginary and the consolidation of what I call 'negative leadership'. Psychoanalysis is the theoretical support for our considerations, especially regarding repetition.

Keywords: leadership, collectivity, May 1968, cycle of struggles, psychoanalysis. 


\section{(Co)mmémorer mai 1968 : l’imaginaire anarchiste et le leadership négatif}

Résumé : En 2018 les « événements de mai 1968 » co-mmémorent 50 ans. Au Brésil, nous co-mmémorons les cinq ans de juin 2013, ce qui fait partie du « cycle de combats ». Ces deux moments font toujours encore penser à eux, malgré le temps coulé. Étant fini en tant qu'acte, ils continuent à exister comme affect et effet. Ils font donc partie d'une certaine mémoire collective, d'une co-mmémoire, permettant un partage d'après de ce qui vient après. Ce sont des signifiés, des sens et des restes qui se manifestent dans le champ sociopolitique et dans le champ de la « subjectivité collective ». Dans ce travail on cible deux éléments similaires de tels événements : l'imaginaire anarchiste qu'ils évoquent et la consolidation de ce qu'on nomme le « leadership négatif ». La psychanalyse sert de support théorique aux réflexions, notamment en ce qui concerne les répétitions.

Mots-clés : leadership, collective, mai 1968, cycle de combats, psychanalyse.

\section{(Con)memorar mayo de 1968: el imaginario anarquista y el liderazgo negativo}

Resumen: En 2018, los "acontecimientos de mayo de 1968" con-memoran cincuenta años. En Brasil, con-memoramos los cinco años del junio de 2013, parte del compuesto "ciclo de luchas". Estos dos momentos tienen en común, entre otras cosas, el hecho de nos hace pensar en ellos hasta hoy, pues, a pesar de haber finalizado mientras acto, permanecen sus efectos y afectos. Forman parte de la memoria colectiva, de una co-memoria, que permite la participación conjunta a consecuencia de lo que nos han dejado. Son significativos, sentidos y restos que se manifiestan en el campo sociopolítico y en el campo de la "subjetividad colectiva". En este trabajo destaco dos elementos semejantes de tales eventos: el imaginario anarquista que los caracterizó y también la consolidación de lo que se denominó "liderazgo negativo". El psicoanálisis sirve como soporte teórico para las consideraciones, específicamente en la cuestión de aquello que se repite.

Palabras clave: liderazgo, colectividad, mayo de 1968, ciclo de luchas, psicoanálisis.

\section{Referências}

Badiou, A. (2012). Somos ainda contemporâneos de Maio de 1968. In A. Badiou, A hipótese comunista (pp. 27-60). São Paulo, SP: Boitempo. (Trabalho original publicado em 2009)

Bernardo, J. (2008). Estudantes e trabalhadores no maio de 68. Revista Lutas Sociais, (19-20), 22-31.

Besancenot, O., \& Löwy, M. (2016). Afinidades revolucionárias. São Paulo, SP: Editora Unesp.

Cohn-Bendit, Daniel. (2008). Forget 68. Paris: Editions de L'Aube.

Deleuze, G., \& Guattari, F. (2015). Maio de 68 não ocorreu. Trágica: Estudos de Filosofia da Imanência, 8(1), 199-121. (trabalho original publicado em 1984)

Ferreira, J. M. C. (2018). Anarquia e maio de 1968 na França. Verve, (33), 15-45.

Ferreira, P. P. (2018a). Coletividade e histeria: psicanálise e manifestações sociais. Revista Polis e Psique, $8(2), 67-92$.

Ferreira, P. P. (2018b). O cartel psicanalítico e os limites de sua escala lógica. Revista Subjetividades, 18(1): 23-33.

Freud, S. (1996). Recordar, repetir, elaborar (novas recomendações sobre a técnica da psicanálise II). In Edição standard brasileira das obras psicológicas completas de Sigmund Freud (J. Salomão, Trad., Vol. 12, pp. 161-171). Rio de Janeiro, RJ: Imago. (Trabalho original publicado em 1914)

Freud, S. (1996). Psicologia de grupo e análise do ego. In Edição standard brasileira das obras psicológicas completas de Sigmund Freud, Vol. 18, pp. 79-154). Rio de Janeiro, RJ: Imago. (Trabalho original publicado em 1921)

Ibáñez Gracia, T. (2014). Anarquismo es movimiento: anarquismo, postanarquismo y neoanarquismo. Barcelona: Virus.

Lacan, J. (1985). O seminário, livro 11: os quatro conceitos fundamentais da psicanálise, 1964. Rio de Janeiro, RJ: Zahar.

Lacan, J. (1992). O seminário, livro 17: o avesso da psicanálise, 1969-1970. Rio de Janeiro, RJ: Zahar.

Lacan, J. (2003). A psiquiatria inglesa e a guerra. In Outros escritos (pp. 106-126). Rio de Janeiro, RJ: Zahar. (Trabalho original publicado em 1947)

Lacan, J. (2003). Ato de fundação. In Outros escritos (pp. 235-247). Rio de Janeiro, RJ: Zahar. (Trabalho original publicado em 1964)

Matos, O. (1989). Paris 1968: as barricadas do desejo. São Paulo, SP: Brasiliense. (Trabalho original publicado em 1981) 
Nunes, R. (2013). A organização dos sem organização: oito conceitos para pensar o "inverno brasileiro". Le Monde Diplomatique Brasil. Recuperado de https:// bit.ly/2F7377y

Nunes, R. (2017). Uma ou duas melancolias? 1917, 1968 e o retorno à questão da organização. Crise e Crítica, l(1), 134-148.
Rancière, J. (2002). O mestre ignorante: cinco lições sobre a emancipação intelectual. Belo Horizonte, MG: Autêntica. Soler, C. (2016). O que faz laço? São Paulo, SP: Escuta.

Recebido: 24/05/2019

Revisado: 01/11/2019

Aprovado: 13/08/2020 